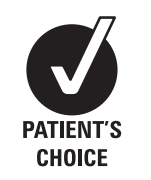
Sciences, Uppsala University Hospital, Uppsala, Sweden; ${ }^{2}$ Department of Public Health and Clinical Medicine, Umeå University Hospital, Umeå

Sweden; ${ }^{3}$ Institute of Environmental Medicine, Karolinska Institute, Stockholm, Sweden; ${ }^{4}$ Department of Laboratory Medicine, Lund University Hospital, Lund, Sweden; ${ }^{5}$ Department of Neurology, Lund University Hospital, Lund, Sweden; ${ }^{6}$ Drug and Therapeutic Committee, County Council of Uppsala, Uppsala, Sweden

Correspondence to: Dr A Terént, Department of Medical Sciences, Uppsala University Hospital, SE-75185 Uppsala, Sweden; andreas. terent@medsci.uu.se

Received 28 November 2008 Revised 19 February 2009

Accepted 20 February 2009

Published Online First

29 March 2009

\title{
Stroke unit care revisited: who benefits the most? A cohort study of 105043 patients in Riks-Stroke, the Swedish Stroke Register
}

\author{
A Terént, ${ }^{1}$ K Asplund, ${ }^{2}$ B Farahmand ${ }^{3}$ K M Henriksson, ${ }^{4}$ B Norrving, ${ }^{5}$ B Stegmayr, ${ }^{2}$ \\ P-0 Wester, ${ }^{2}$ K H Åsberg, ${ }^{6}$ S A sberg, ${ }^{1}$ for the Riks-Stroke Collaboration
}

\begin{abstract}
Background: Treatment at stroke units is superior to treatment at other types of wards. The objective of the present study is to determine the effect size of stroke unit care in subgroups of patients with stroke. This information might be useful in a formal priority setting.
\end{abstract}

Methods: All acute strokes reported to the Swedish Stroke Register from 2001 through 2005 were followed until January 2007. The subgroups were age (18-64, 6574, 75-84, 85+ years and above), sex (male, female), stroke subtype (intracerebral haemorrhage, cerebral infarction and unspecified stroke) and level of consciousness (conscious, reduced, unconscious). Cox proportional hazards and logistic regression analyses were used to estimate the risk for death, institutional living or dependency.

Results: 105043 patients were registered at 86 hospitals. 79689 patients (76\%) were treated in stroke units and 25354 patients (24\%) in other types of wards. Stroke unit care was associated with better long-term survival in all subgroups. The best relative effect was seen among the following subgroups: age 18-64 years (hazard ratio (HR) for death $0.53 ; 0.49$ to 0.58 ), intracerebral haemorrhage (HR $0.61 ; 0.58$ to 0.65 ) and unconsciousness (HR 0.70; 0.66 to 0.75). Stroke unit care was also associated with reduced risk for death or institutional living after 3 months.

Conclusions: Stroke unit care was associated with better long-term survival in all subgroups, but younger patients, patients with intracerebral haemorrhage and patients who were unconscious had the best relative effect and may be given the highest priority to this form of care.

Controlled clinical trials have shown that stroke unit care is superior to stroke care at other types of wards. A review shows that treatment in a stroke unit reduces the risk of death by almost $20 \%,{ }^{1}$ and a review of observational studies confirms this observation. $^{2}$ In guidelines, stroke unit care is recommended for patients with acute stroke in England, Sweden and other countries. ${ }^{3-6}$ The National Sentinel Audit for Stroke of 2006, showed that stroke units have been established in $91 \%$ of English hospitals. ${ }^{7}$ The Stroke Unit Survey in Sweden of 2005 found that $86 \%$ of Swedish hospitals have stroke units. ${ }^{8}$

In spite of this expansion, there is a shortage of stroke unit beds, and allocation to stroke unit care may be challenging. In England, $62 \%$ of the patients were treated in stroke units in $2006 .^{7}$ In Sweden, $52 \%$ of the hospitals reported that all or almost all patients (>90\%) were admitted to their stroke unit in $2005 .{ }^{8}$ In the other hospitals, patients were allocated to stroke units and other types of wards, depending on access to stroke unit beds.

\section{OBJECTIVES}

Knowledge about treatment effects in stroke subgroups is limited. In clinical trials, no difference has been found between men and women, patients younger or older than 75 years, and patients with severe or less severe stroke. ${ }^{1}$ The objective of the present study is to determine the effect size of stroke unit care in subgroups of patients with stroke. This information might be useful in a formal priority setting.

\section{METHODS}

\section{Study design}

A cohort study of acute stroke care, at a nonintensive stroke unit compared with stroke care at other types of wards, was performed.

\section{Setting}

All patients reported to Riks-Stroke, the Swedish Stroke Register. In Sweden there were 9 million inhabitants and 86 hospitals treating patients with stroke during the study period. All hospitals delivered data to Riks-Stroke. The registration of data in Riks-Stroke has been described in detail in previous publications. ${ }^{9}{ }^{10}$

The Riks-Stroke registration consists of two parts. The first is a case record form (CRF) which is completed in the acute phase by members of the hospital staff. Patients are characterised in the CRF with respect to: activities of daily living (ADL) function and living conditions before stroke, cardiovascular risk factors and their treatment, level of consciousness ${ }^{11}$ on arrival at hospital and brain imaging. Stroke care is documented in the CRF with respect to: admission ward (first ward after leaving the emergency room) and continued care ward (second ward in the case of a change), length of stay and discharge destination. The second part of the Riks-Stroke registration is a questionnaire, which is completed by the patient or relatives after 3 months. ${ }^{9}{ }^{12}$ In the questionnaire, new data on ADL function, living conditions and general health are collected. Detailed information about the register, including an English translation of the CRF and the questionnaire, can be accessed at the Riks-Stroke website (http://www.riksstroke.org). 


\section{Participants and data sources}

All patients who were registered in Riks-Stroke during the period 1 January 2001 through 31 December 2005 were included. The WHO definition of an acute stroke was used. ${ }^{9}$ The following ICD 10 code diagnoses were registered by all hospitals: intracerebral haemorrhage (I 61), cerebral infarction (I 63) and unspecified stroke (I 64). The sample size of the study would ensure detailed subgroup analyses.

Cross-linking to the Swedish Hospital Discharge and Cause of Death registers was done to achieve data on previous hospitalisations and death dates respectively. This was possible by using the unique personal identification number, which all Swedish inhabitants have. Previous hospitalisations were traced back to 1 January 1987. Vital status (death date) was followed until 31 January 2007.

\section{Variables}

The impact of stroke unit care compared with care at other types of wards was studied with respect to death or institutional living (alternatively death or dependency) after 3 months and death during the whole follow-up period (mean 2.4 years). The effect of missing registrations in Riks-Stroke has been validated previously. ${ }^{13}$ The effect of missing values within a registration has been handled by not including these registrations in the statistical models. The number of missing data is given in text and tables.

\section{Statistical methods}

SPSS version 15.01.1 was used for all analyses. Patient characteristics in the different treatment groups were compared using $\chi^{2}$ test for categorical and ANOVA for continuous variables. All tests were two-tailed.

Cox proportional hazards was used to estimate the death hazard during follow-up, and logistic regression analysis to estimate the odds ratio for death or institutional living (alternatively death or dependency) after 3 months. Twelve covariates (predictor variables) were included simultaneously and adjusted for each other in the final model (table 1). There were 10 categorical predictor variables: stroke unit, sex, haemorrhagic stroke, reduced level of consciousness, $\mathrm{ADL}$ dependency, institutional living, previous stroke, atrial fibrillation, diabetes and treated hypertension, and two continuous: age and number of previous hospitalisations. Most of the predictor variables have been identified in previous studies. ${ }^{9}{ }^{10}$ The number of previous hospitalisations, reflecting comorbidity, was significantly associated with the outcome in simple logistic regression and therefore included in the model. Hospital size was on the other hand not significantly associated with outcome and therefore not included in the final model. The number of outcome events was high in the study cohort, ranging from 2218 to 36064 . Thus, the ratio of outcome events to the number of predictor variables was very high, ranging from 185 to 3005 .

When performing logistic regression or Cox regression, the method ENTER in SPSS was used because all predictor variables were considered equally important to the model and therefore entered at the same time. Interaction terms were considered, and the following interaction parameters were introduced in the models: age $\times$ stroke unit, sex $\times$ stroke unit, stroke subtype $\times$ stroke unit and level of consciousness $\times$ stroke unit. Interaction was tested at the $\alpha=0.01$ level. Tests for collinearity were performed by bivariate correlation analyses. The highest correlation coefficient, 0.474 , was achieved for ADL dependency and institutional living. Overall-model-fit and regression diagnostics were performed according to standard procedures. The final models were able to predict outcome by more than $80 \%$ according to the classification table of SPSS.

Finally, Kaplan-Meier curves were plotted and a logrank test performed. The latter is a test of equality of survival distributions for the different levels of stroke unit care versus care at all other wards.

\section{Ethics approval}

The present study has been approved by the Ethical Committee of Umeå University Hospital, 5 May 2006, Reg. No. 69106.

\section{RESULTS}

The total number of patients was 105043 and the mean followup time 2.4 years, making a total of 254824 patient years. A total of 79689 patients $(75.9 \%$ ) were provided stroke unit care, and $25354(24.1 \%)$ were provided care at other types of wards. CT of the brain was performed in $97.2 \%$ of the patients. The proportion of patients who were initially treated in intensive care units was $3.7 \%, 3.1 \%$ among patients treated in stroke units and $5.5 \%$ among patients treated in other types of wards. The proportion of patients who were discharged for additional rehabilitation was $20.6 \%, 19.7 \%$ among patients treated in stroke units and $23.5 \%$ among patients treated in other types of wards. The time spent at hospital, including in-hospital rehabilitation, was 18.4 (19.1 SD) days in patients treated at stroke units and 14.7 (17.4 SD) in patients treated at other types of wards. The response rate at the 3-month follow-up was $87.1 \%$. The number of patients with missing follow-up data, for dependency or institutional living, was 10092 (12.7\%) in stroke units and $3437(13.6 \%)$ in other types of wards. No patient was lost to follow-up of death date.

The distribution of baseline characteristics among patients treated at stroke units and other types of wards is shown in table 1. Overall, the characteristics of stroke unit patients were more favourable. Therefore, all baseline characteristics were included in the statistical models, when hazards ratios and odds ratios were calculated (see Statistical methods).

\section{Absolute differences}

The proportion of patients who were dead or institutionalised after 3 months is shown in table 3 . The largest difference in absolute terms was found among patients with haemorrhagic stroke $(18.8 \%$ fewer) and among patients 64 years of age or lower $(10.9 \%$ fewer).

The death rate during the whole follow-up is shown in table 2. Patients at stroke units had substantially lower death rates in all subgroups. The largest differences in absolute terms were seen among patients with haemorrhagic stroke (200 per 1000 patient-years) and unconscious patients (878 per 1000 patientyears). The Kaplan-Meier curves show that the risk reduction in these groups comes early and is durable (figs 1,2). With regard to age, patients 85 years and older seemed to have the largest reduction in death rate, 94 per 1000 patient years compared with 54 among patients below 85 years of age. For men and women, a similar reduction was found, 71 and 74 per 1000 patient years respectively. The frequency of death or dependency after 3 months is shown in table 4 . The largest absolute difference was seen among patients with haemorrhagic stroke (16.1\% fewer). Bias caused by those cases who were lost to follow-up was estimated. Assuming that all patients lost to follow-up were dependent, after 3 months, this would change 
Table 1 Distribution of baseline characteristics among 79689 patients treated at stroke units and 25354 patients treated at other types of wards

\begin{tabular}{|c|c|c|c|c|c|c|}
\hline & \multicolumn{2}{|c|}{ Stroke unit } & \multicolumn{2}{|c|}{ Other types of wards } & \multirow{2}{*}{$\begin{array}{l}\text { Test } \\
\text { p Value }\end{array}$} & \multirow{2}{*}{$\begin{array}{l}\text { Data missing } \\
\text { n (\%) }\end{array}$} \\
\hline & n & $\%$ & n & $\%$ & & \\
\hline Male sex & 40668 & 51.0 & 12043 & 47.5 & $<0.001$ & $0(0)$ \\
\hline Haemorrhagic stroke & 9265 & 11.6 & 3232 & 12.7 & $<0.001$ & $0(0)$ \\
\hline Lowered level of consciousness & 13224 & 16.8 & 5881 & 23.7 & $<0.001$ & $1324(1.3)$ \\
\hline Activities of daily living dependency* & 9684 & 12.3 & 4020 & 16.5 & $<0.001$ & $1810(1.7)$ \\
\hline Institutional living & 6210 & 7.8 & 3048 & 12.2 & $<0.001$ & $886(0.8)$ \\
\hline Previous stroke & 16764 & 21.0 & 5572 & 22.0 & 0.001 & $2304(2.2)$ \\
\hline Atrial fibrillation & 19889 & 25.0 & 6646 & 26.2 & $<0.001$ & $2958(2.8)$ \\
\hline Diabetes & 16000 & 20.1 & 4965 & 19.6 & 0.087 & $1596(1.5)$ \\
\hline \multirow[t]{2}{*}{ Treatment for hypertension } & 39198 & 49.1 & 11516 & 45.4 & $<0.001$ & $2930(2.8)$ \\
\hline & Mean & SD & Mean & SD & p Value & n (\%) \\
\hline Age & 75.1 & 11.2 & 77.0 & 5.2 & $<0.001$ & $0(0)$ \\
\hline No of previous hospitalisations & 4.7 & 5.3 & 5.2 & 5.7 & $<0.001$ & $403(0.4)$ \\
\hline
\end{tabular}

${ }^{*}$ Activities of daily living dependency, according to the definition of the present paper, was equivalent to a modified Rankin Scale score of $4-5$ in a cohort of 545 patients, ${ }^{21}$ who were investigated 3 months after hospitalisation (personal communication, Marie Eriksson, 2008).

the odds ratio (OR) for death or dependency by 0.07. Supposing that all lost patients were independent, this would change the OR for death or dependency by 0.06 .

\section{Relative differences}

In the Cox and logistic regression analyses, a statistically significant interaction existed between subgroup (age, stroke subtype and level of consciousness) and stroke unit care on outcome. For that reason, statistical modelling within each subgroup was relevant to control for confounders.

The largest reduction of the death hazard, during the whole follow-up, was found among the youngest patients (HR 0.53; 0.49 to 0.58 ), patients with intracerebral haemorrhage (HR 0.61;
0.58 to 0.65 ) and unconscious patients (HR $0.70 ; 0.66$ to 0.75 ) (table 5)

The most important reduction in the odds for death or institutional living, after 3 months, was seen in unconscious patients (OR $0.47 ; 0.39$ to 0.57 ), patients with intracerebral haemorrhage (OR 0.56; 0.50 to 0.61 ) and the youngest patients (OR $0.60 ; 0.54$ to 0.68 ). The odds reduction for death or dependency, after 3 months, was also large among patients with intracerebral haemorrhages and unconsciousness, while it was modest among young patients (table 5).

In our cohort, there were 17496 patients (16.7\%) below the age of 65 years, 12497 patients (11.9\%) with intracerebral haemorrhage and 5693 patients (5.4\%) who were unconscious
Figure 1 Kaplan-Meier curves for stroke subtypes. Patients were treated at stroke units (SU) and other types of wards.
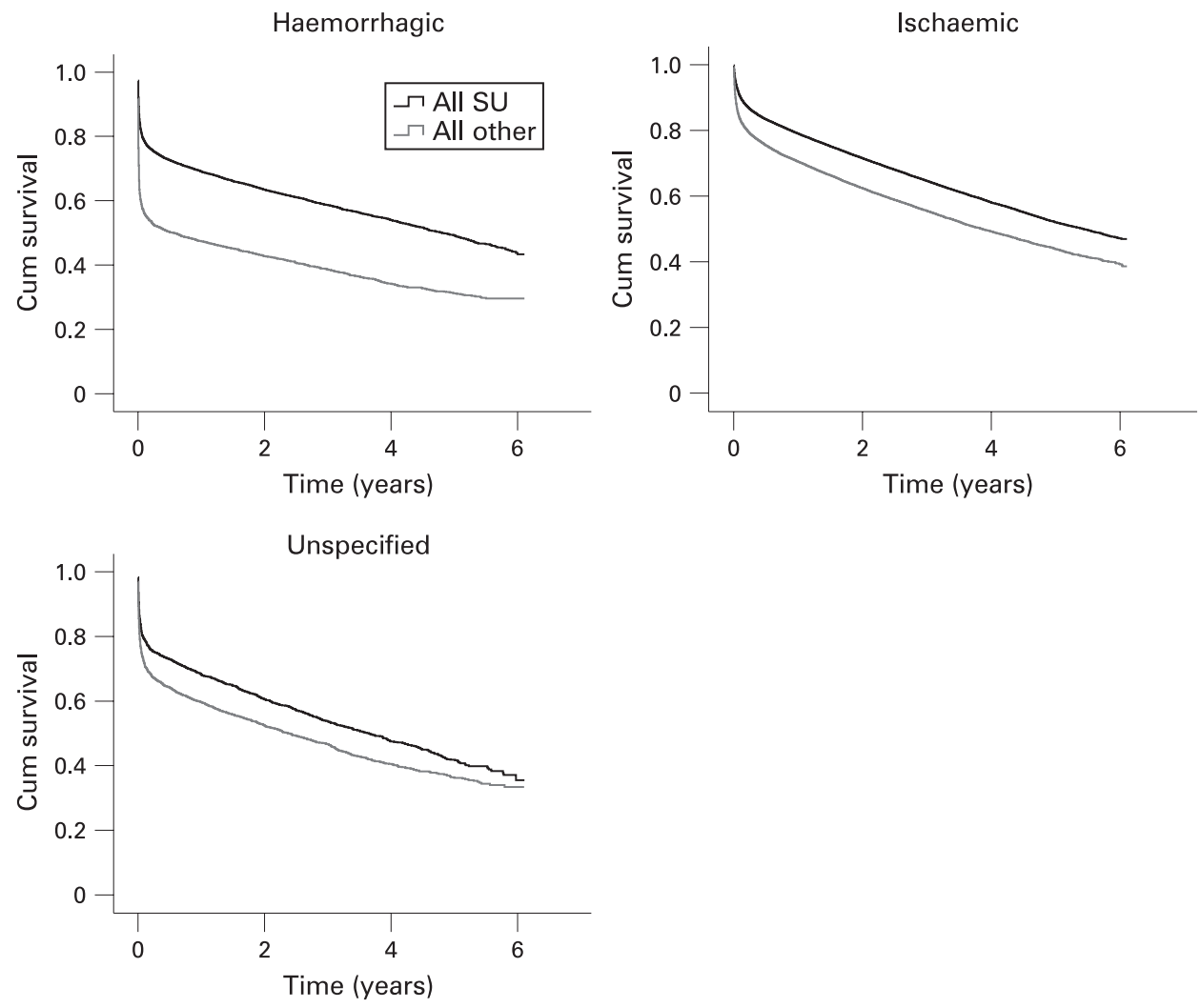
Figure 2 Kaplan-Meier curves by level of consciousness. Patients treated at stroke units (SU) and other types of wards.
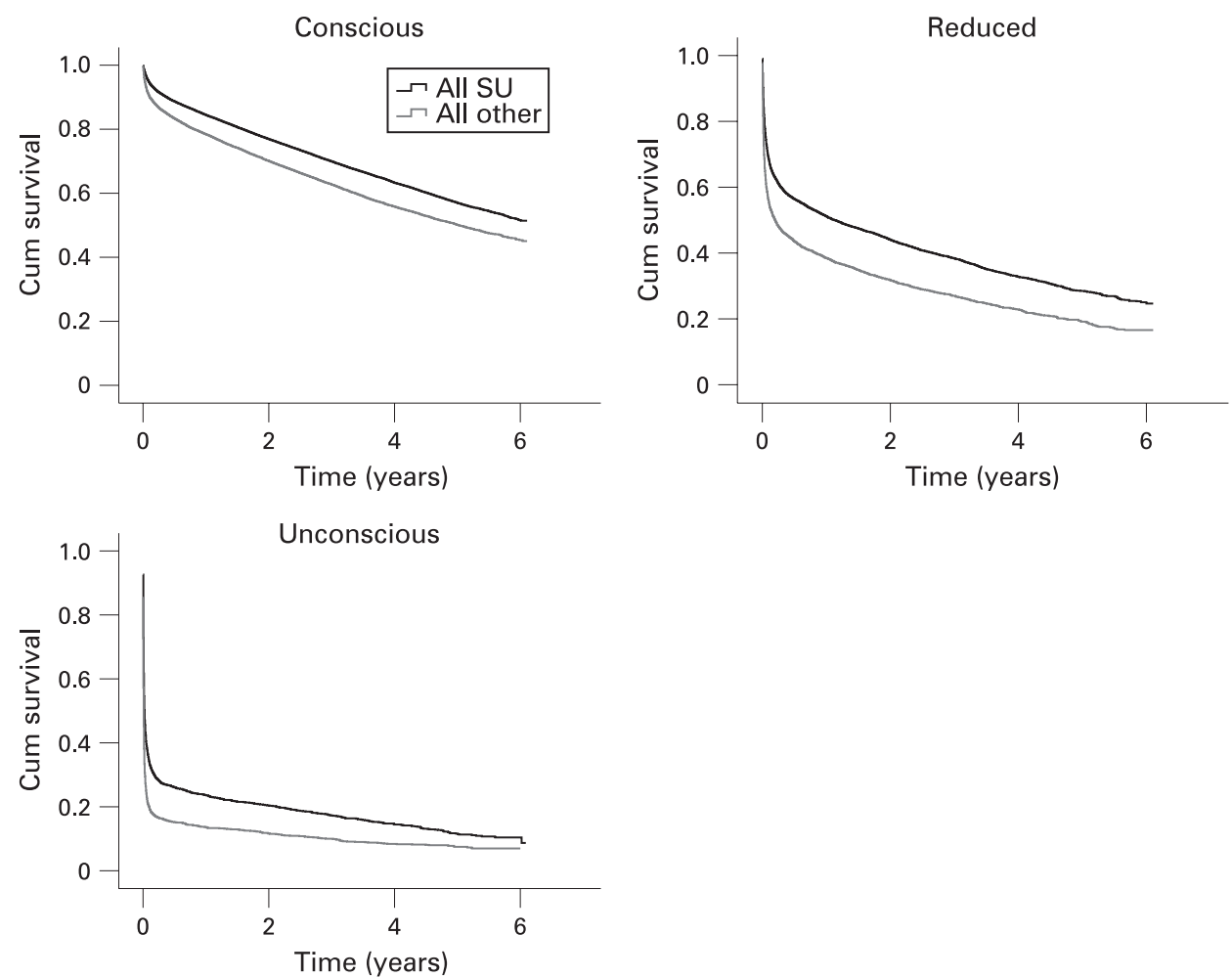

on admission. Taking overlap between these indicators of marked beneficial effects of stroke unit care into account, there were 29696 patients (28.3\%) that belonged to at least one of the three high-benefit groups.

\section{DISCUSSION}

\section{Principal findings}

In this large cohort of hospitalised patients with stroke, stroke unit care had a beneficial effect in most subgroups. The largest effect size was found among patients younger than 65 years, patients with intracerebral haemorrhages and patients with lowered level of consciousness. In a formal priority setting, these subgroups could be easily identified. They constitute a reasonably small proportion, less than $30 \%$ of all patients, making their prioritisation smooth in most instances.

The relative benefits of stroke unit care were clearly higher for patients below the age of 65 than for elderly patients with stroke, in particular for survival. However, since case fatality rates are much higher among elderly patients, the picture becomes different when risk reductions are expressed in absolute rather than relative terms. The absolute risk reduction for stroke unit care versus care in other wards was actually higher among the oldest patients (94 per 1000 patient-years)

Table 2 Death during the whole follow-up period according to stroke subgroup and type of hospital ward

\begin{tabular}{|c|c|c|c|c|c|c|c|c|}
\hline \multirow[b]{2}{*}{ Subgroup } & \multicolumn{4}{|c|}{ Stroke units ( $\mathrm{n}=79$ 689) } & \multicolumn{4}{|c|}{ Other wards ( $n=25354$ ) } \\
\hline & Total & Dead & PY & $\begin{array}{l}\text { Deaths/ } \\
1000 \text { PY }\end{array}$ & Total & Dead & PY & $\begin{array}{l}\text { Deaths/ } \\
1000 \text { PY }\end{array}$ \\
\hline \multicolumn{9}{|l|}{ Age } \\
\hline 18-64 years & 14068 & 1555 & 45012 & 34.5 & 3428 & 797 & 10158 & 78.5 \\
\hline $65-74$ years & 18029 & 4462 & 52684 & 84.6 & 4962 & 1666 & 13892 & 119.9 \\
\hline $75-84$ years & 31517 & 14255 & 75001 & 190.1 & 10308 & 5596 & 22844 & 245.0 \\
\hline$\geqslant 85$ years & 16075 & 10959 & 25695 & 426.5 & 6656 & 4987 & 9573 & 520.9 \\
\hline \multicolumn{9}{|l|}{ Sex } \\
\hline Male & 40668 & 14804 & 105036 & 140.9 & 12043 & 5871 & 27755 & 211.5 \\
\hline Female & 39021 & 16427 & 93356 & 176.0 & 13311 & 7175 & 28711 & 249.9 \\
\hline \multicolumn{9}{|l|}{ Stroke subtype } \\
\hline Haemorrhagic & 9265 & 4062 & 20992 & 193.5 & 3232 & 2069 & 5248 & 394.2 \\
\hline Ischaemic & 67823 & 25877 & 171596 & 150.8 & 19288 & 9390 & 45855 & 204.8 \\
\hline Unspecified & 2601 & 1292 & 5804 & 222.6 & 2834 & 1587 & 5364 & 295.7 \\
\hline \multicolumn{9}{|l|}{$\begin{array}{l}\text { Level of } \\
\text { consciousness }\end{array}$} \\
\hline Conscious & 65682 & 21661 & 178051 & 121.7 & 18932 & 7888 & 49911 & 158.0 \\
\hline Reduced & 9783 & 6277 & 15964 & 393.2 & 3629 & 2746 & 4532 & 605.9 \\
\hline Unconscious & 3441 & 2894 & 2603 & 1111.8 & 2252 & 2043 & 1027 & 1989.3 \\
\hline
\end{tabular}

PY, person-years. 
Table 3 Death or institutional living after 3 months according to stroke subgroup and type of hospital ward

\begin{tabular}{|c|c|c|c|c|c|c|}
\hline \multirow[b]{2}{*}{ Subgroup } & \multicolumn{3}{|c|}{ Stroke units $(n=79689)$} & \multicolumn{3}{|c|}{ Other wards ( $\mathrm{n}=25354$ ) } \\
\hline & Total & $\begin{array}{l}\text { Dead or } \\
\text { institutional }\end{array}$ & Percentage & Total & $\begin{array}{l}\text { Dead or } \\
\text { institutional }\end{array}$ & Percentage \\
\hline \multicolumn{7}{|l|}{ Age } \\
\hline $18-64$ years & 14068 & 1552 & 11.0 & 3428 & 751 & 21.9 \\
\hline $65-74$ years & 18029 & 3376 & 18.7 & 4962 & 1270 & 25.6 \\
\hline $75-84$ years & 31517 & 10405 & 33.0 & 10308 & 4030 & 39.1 \\
\hline$\geqslant 85$ years & 16075 & 8616 & 53.6 & 6656 & 3923 & 58.9 \\
\hline \multicolumn{7}{|l|}{ Sex } \\
\hline Male & 40668 & 10418 & 25.6 & 12043 & 4222 & 35.1 \\
\hline Female & 39021 & 13531 & 34.7 & 13311 & 5752 & 43.2 \\
\hline \multicolumn{7}{|l|}{ Stroke subtype } \\
\hline Haemorrhagic & 9265 & 3818 & 41.2 & 3232 & 1938 & 60.0 \\
\hline Ischaemic & 67823 & 19168 & 28.3 & 19288 & 6781 & 35.2 \\
\hline Unspecified & 2601 & 963 & 37.0 & 2834 & 1255 & 44.3 \\
\hline \multicolumn{7}{|l|}{$\begin{array}{l}\text { Level of } \\
\text { consciousness }\end{array}$} \\
\hline Conscious & 65682 & 14542 & 22.1 & 18932 & 5107 & 27.0 \\
\hline Reduced & 9783 & 6186 & 63.2 & 3629 & 2535 & 69.9 \\
\hline Unconscious & 3441 & 2869 & 83.4 & 2252 & 2050 & 91.0 \\
\hline
\end{tabular}

than among younger patients (54 per 1000 patient-years). Taking relative as well as absolute risk reductions into account, it may seem unjustified to base priority setting for stroke unit care on age per se.

The gender perspective has been considered in previous studies. The odds ratio for death or institutional living has not been different among men and women in the controlled clinical trials, ${ }^{1}$ and no difference was found in the Italian study. ${ }^{14}$ Thus, data from all studies presented so far, controlled clinical trials as well as observational studies, confirm that both sexes benefit from stroke unit care.

As regards stroke subtype, no data have been presented from controlled clinical trials, probably depending on a low frequency of brain imaging in older studies. ${ }^{1}$ In the review of observational stroke unit studies, it was not possible to analyse ischaemic and haemorrhagic stroke separately due to insufficient data. ${ }^{2}$ In the Italian study, a significantly better effect was achieved by stroke unit care in patients with haemorrhagic stroke. ${ }^{14}$ Thus, there is now evidence from two large observational studies, the present study and the Italian study, that patients with haemorrhagic stroke benefit more from stroke unit care than patients with ischaemic stroke.

For stroke severity, there are some important issues to consider before conclusions can be made. In the review of controlled clinical trials, strokes were divided into mild, moderate and severe, based on the Barthel ADL index or an equivalent index. ${ }^{1}$ In that review, a positive effect of stroke unit care was achieved only among patients with severe stroke. In the review of observational studies, "better" and "worse" patients showed equally good results of stroke unit care. There is however no clear definition of these groups in the publication. ${ }^{2}$ In the Italian study, stroke severity was characterised by the level of consciousness, and patients were dichotomised into "conscious and unconscious."14 The classification was done retrospectively based on a review of patients' clinical records. No statistically significant difference was found between these two groups. In the present study, a modified version of the Scandinavian Reaction Level Scale was used. Scoring according

Table 4 Death or dependency after 3 months according to stroke subgroup and type of hospital ward

\begin{tabular}{|c|c|c|c|c|c|c|}
\hline \multirow[b]{2}{*}{ Subgroup } & \multicolumn{3}{|c|}{ Stroke units ( $n=79$ 689) } & \multicolumn{3}{|c|}{ Other wards ( $n=25354$ ) } \\
\hline & Total & $\begin{array}{l}\text { Dead or } \\
\text { dependency }\end{array}$ & Percentage & Total & $\begin{array}{l}\text { Dead or } \\
\text { dependency }\end{array}$ & Percentage \\
\hline \multicolumn{7}{|l|}{ Age } \\
\hline 18-64 years & 11819 & 2435 & 20.6 & 2857 & 896 & 31.4 \\
\hline $65-74$ years & 15945 & 5603 & 35.1 & 4326 & 1727 & 39.9 \\
\hline $75-84$ years & 27528 & 14676 & 53.3 & 8919 & 5226 & 58.6 \\
\hline$\geqslant 85$ years & 13959 & 10497 & 75.2 & 5721 & 4613 & 80.6 \\
\hline \multicolumn{7}{|l|}{ Sex } \\
\hline Male & 35406 & 14542 & 41.1 & 10412 & 5241 & 50.3 \\
\hline Female & 33845 & 18669 & 55.2 & 11411 & 7221 & 63.3 \\
\hline \multicolumn{7}{|l|}{ Stroke subtype } \\
\hline Haemorrhagic & 8206 & 4752 & 59.2 & 2871 & 2161 & 75.3 \\
\hline Ischaemic & 58989 & 27260 & 46.2 & 16535 & 8804 & 53.2 \\
\hline Unspecified & 2236 & 1199 & 53.6 & 2417 & 1497 & 61.9 \\
\hline \multicolumn{7}{|c|}{ Level of consciousness } \\
\hline Conscious & 56851 & 22679 & 39.9 & 16071 & 7285 & 45.3 \\
\hline Reduced & 8552 & 7110 & 83.1 & 3171 & 2774 & 87.5 \\
\hline Unconscious & 3207 & 2985 & 93.1 & 2167 & 2086 & 96.3 \\
\hline
\end{tabular}


Table 5 Outcome of stroke unit care compared with stroke care at other types of wards

\begin{tabular}{|c|c|c|c|}
\hline & $\begin{array}{l}\text { Hazard ratio for death at } \\
\text { the end of follow-up, } \\
\text { mean } 2.4 \text { years }\end{array}$ & $\begin{array}{l}\text { OR for death or institutional } \\
\text { living after } 3 \text { months }\end{array}$ & $\begin{array}{l}\text { OR for death or dependency } \\
\text { after } 3 \text { months }\end{array}$ \\
\hline Subgroups & HR (95\% CI) & OR (95\% Cl) & OR $(95 \%$ Cl) \\
\hline \multicolumn{4}{|l|}{ Age } \\
\hline 18-64 years & $0.53(0.49$ to 0.58$)$ & $0.60(0.54$ to 0.68$)$ & $0.84(0.75$ to 0.93$)$ \\
\hline $65-74$ years & $0.78(0.73$ to 0.82$)$ & $0.79(0.73$ to 0.87$)$ & 0.99 (0.91 to 1.08$)$ \\
\hline $75-84$ years & 0.81 (0.79 to 0.84$)$ & $0.91(0.86$ to 0.96$)$ & 0.98 (0.92 to 1.03 ) \\
\hline$\geqslant 85$ years & $0.86(0.83$ to 0.89$)$ & $0.90(0.84$ to 0.97$)$ & 0.83 (0.76 to 0.91$)$ \\
\hline \multicolumn{4}{|l|}{ Sex } \\
\hline Male & $0.79(0.76$ to 0.81$)$ & $0.82(0.78$ to 0.86$)$ & $0.91(0.86$ to 0.96$)$ \\
\hline Female & $0.83(0.81$ to 0.85$)$ & 0.88 (0.83 to 0.92$)$ & 0.95 (0.90 to 1.00$)$ \\
\hline \multicolumn{4}{|l|}{ Stroke subtype } \\
\hline Haemorrhagic & 0.61 (0.58 to 0.65$)$ & $0.56(0.50$ to 0.61$)$ & 0.59 (0.53 to 0.67 ) \\
\hline Ischaemic & $0.87(0.85$ to 0.89$)$ & $0.92(0.88$ to 0.95$)$ & 0.98 (0.94 to 1.03 ) \\
\hline Unspecified & $0.92(0.85$ to 0.99$)$ & 0.94 (0.81 to 1.09 ) & 0.96 (0.82 to 1.12$)$ \\
\hline \multicolumn{4}{|l|}{ Level of consciousness } \\
\hline Conscious & $0.88(0.85$ to 0.90$)$ & $0.91(0.88$ to 0.95$)$ & $0.97(0.93$ to 1.01$)$ \\
\hline Reduced consciousness & 0.78 (0.74 to 0.82$)$ & 0.84 (0.77 to 0.92$)$ & 0.86 (0.75 to 0.98$)$ \\
\hline Unconscious & $0.70(0.66$ to 0.75$)$ & $0.47(0.39$ to 0.57$)$ & $0.47(0.36$ to 0.62$)$ \\
\hline
\end{tabular}

Adjusted hazard ratios (HR) and odds ratios (OR) are presented for each level within the four subgroups.

to this scale has been used in critical care in Sweden for 20 years, and the scale is well known to most Swedish physicians. The present finding of improved outcome after stroke unit care among patients with lowered level of consciousness is coherent with the findings of previous studies showing a beneficial effect in patients with severe stroke. ${ }^{12} 14$

\section{Strengths and weaknesses of the study}

The present study is large, allowing for detailed subgroup analyses with narrow confidence intervals. It is a prospective register study, including more than $80 \%$ of patients with acute stroke in Sweden. ${ }^{15}$ Several predictor variables, known from previous analyses and the literature, could be used when adjusting for differences in case mix. ${ }^{910} 16$ These include previous stroke, atrial fibrillation, $\mathrm{ADL}$ dependency and institutional living before stroke, all strong predictors for death. It was also possible to adjust for previous hospitalisations, reflecting comorbidity. There was no loss to follow-up with regard to long-term survival.

The observational study design bears an inherent risk of imbalance with regard to confounders between patients treated at stroke units and other types of wards. It was not possible to specifically control for lesion size, as measured by CT and neurological scales, cardiac disease and cognitive decline, all being potentially important predictors. The level of consciousness, as defined in the present paper, is a reasonable, but not perfect, measure of stroke severity. Its correlation with the NIH stroke scale is just intermediate. Lowered level of consciousness has been correlated with the NIH stroke scale in a populationbased cohort. ${ }^{22}$ The correlation coefficient was 0.373 between lowered level of consciousness, according to Riks-Stroke, and an $\mathrm{NIH}$ stroke scale score $\geqslant 9$ (P Appelros, personal communication, 2008). The correlation was better, 0.545 , for a NIH stroke scale score $\geqslant 21$.

The level of consciousness reflects not only stroke severity, but other factors of importance for short-term survival such as raised body temperature, fluid deficit and high blood glucose. Swedish stroke units have intervention programmes for nutrition and fluid delivery, early activation of the patients and intermittent appraisal of neurological symptoms and vital parameters. The existence of these programmes provides the most plausible explanation for the remarkable effect of stroke unit care in unconscious patients and patients with haemorrhagic stroke.

The impact of registration bias has been discussed in the other publications from the register. ${ }^{10} 1317$ The characteristics of patients lost to follow-up have also been analysed. These patients have been more dependent and institutionalised before stroke $^{9}$ and more afflicted by haemorrhagic stroke and lowered level of consciousness during hospital stay. ${ }^{13}$

\section{Strengths and weaknesses in relation to other studies}

The present study is the largest within this field so far. The review of observational studies included 42000 patients from 18 studies. ${ }^{2}$ The present study is based on a stroke register covering all hospitals and most acute strokes in a country during a 5-year period. The data are prospectively collected on a CRF during the acute phase, and the 3-month follow-up is based on a questionnaire with a response rate of $87 \%$. The Italian study included 11500 of approximately 250000 patients in seven regions during a 5 -year period. ${ }^{14}$ In that study, the data describing patient characteristics were retrospectively collected by review of patients' clinical records. The follow-up was prospectively performed, and $95 \%$ of the follow-up data were complete.

Stroke unit care reduces the risk of death after stroke by prevention and treatment of medical complications, ${ }^{18}$ but the components which have the strongest impact on outcome have not been identified yet. Swedish stroke units are of the nonintensive type with intermittent monitoring of vital parameters but little use of bedside monitors for continuous monitoring. ${ }^{8}$ Use of continuous monitoring is a matter of debate, and evidence for its efficiency in the major part of patients with stroke is still lacking. ${ }^{19} 20$ Use of intensive care was very infrequent, $3-5 \%$, in the present study cohort and did not have any impact on outcome.

In summary, stroke unit care was associated with a better long-term survival in all subgroups, but younger patients, patients with intracerebral haemorrhage and patients who were unconscious had the best relative effect and may be given the highest priority to this form of care. 
Acknowledgements: We want to thank P Appelros (peter.appelros@orebroll.se) for providing data on the correlation between $\mathrm{NIH}$ stroke scale and level of consciousness according to Riks-Stroke. We also want to thank M Eriksson (marie.eriksson@ medicin.umu.se) for providing data on the relationship between modified Rankin Scale and $A D L$ dependency as defined in the present paper. We would also like to thank $F$ Jonsson, MSc, for statistical advice. Finally, we want to thank all the representatives of hospitals contributing data to the Riks-Stroke register.

Funding: The National Board of Health and Welfare and the Federation of Swedish County Councils have sponsored Riks-Stroke. The AstraZeneca Company, Epidemiology Unit, has sponsored the present study.

Competing interests: AT has received a research grant from AstraZeneca. BF and $\mathrm{KH}$ are employed at the Epidemiology Department, AstraZeneca R\&D.

Ethics approval: Ethics approval was provided by the Ethical Committee of Umeå University Hospital.

AT initiated the study, carried out the statistical analyses and drafted the report. BF and $\mathrm{S} \AA$ retrieved and structured data from the databases used. KA, KHA, BN, BS, AT and P-OW were members of the Riks-Stroke steering committee and revised the report. KH also revised the report.

\section{REFERENCES}

1. Stroke Unit Trialists' Collaboration. Organised inpatient (stroke unit) care for stroke (review). Cochrane Database of Syst Rev 2007;(4):CD000197.

2. Seenan $\mathbf{P}$, Long M, Langhorne P. Stroke units in their natural habitat. Stroke 2007;38:1886-92.

3. Anon. National guidelines on stroke care. Stockholm: Socialstyrelsen, 2000.

4. Scottish Intercollegiate Guidelines Network. Management of patients with stroke. Rehabilitation, prevention and management of complications, and discharge planning. A national clinical guideline, 2002. http://www.sign.ac.uk/pdf/sign64.pdf (accessed 15 Apr 2009).

5. Anon. National clinical guidelines for stroke. 2nd edn. Prepared by the Intercollegiate Stroke Working Party, June 2004. http://www.rcplondon.ac.uk/pubs/books/ stroke guidelines 2ed.pdf (accessed 17 Apr 2009).
6. Anon. National guidelines on stroke care, 2005. http://www.socialstyrelsen.se/NR/ rdonlyres/76CD5474-58F3-4984-804E-24FB266BODDC/7484/200710210.pdf (accessed 17 Apr 2009)

7. Mayor S. Stroke care is improving in England but not in Wales, audit shows. BMJ 2007; $334: 969$

8. Anon. Strokeenheter i Sverige. http://www.socialstyrelsen.se/Publicerat/2007/9594/ 2007-123-17.htm (accessed 15 Apr 2009).

9. Stegmayr B, Asplund K, Hulter-Asberg K, et al. Stroke units in their natural habitat. Stroke 1999;30:709-14.

10. Glader E-L. Differences in long-term outcome between patients treated in stroke units and general medical wards: a 2-year follow-up of stroke patients in Sweden. Stroke 2001;32:2124-30.

11. Starmark J, Stålhammar D, Holmgren E, et al. A comparison of the Glasgow Coma Scale and the Reaction Level Scale (RLS85). J Neurosurg 1988;69:699-706.

12. Glader E-L, Stegmayr B, Norrving B, et al. Sex differences in management and outcome after stroke. A Swedish National Perspective. Stroke 2003;34:1970-5.

13. Glader E-L. Stroke care in Sweden [thesis]. Umeå, Umeå University, 2003.

14. Candelise L, Gattinoni M, Bersano A, et al. Stroke-unit care for acute stroke patients: an observational follow-up study. Lancet 2007;369:299-305.

15. Anon. Strokesjukvården i Sverige. http://www.socialstyrelsen.se/Publicerat/2007/ 9594/2007-131-30.htm (accessed 15 Apr 2009).

16. Putman K, De Wit L, Schupp W, et al. Inpatient stroke rehabilitation: a comparative study of admission criteria to stroke rehabilitation units in four European countries. J Rehabil Med 2007;39:21-6.

17. Appelros $\mathbf{P}$, Samuelsson $M$, Karlsson-Tivenius $S$, et al. An national quality register: 12 years experience from a participating hospital. Eur J Neurol 2007:14:890-4.

18. Govan L, Langhorne P, Weir CJ. Does the prevention of complications explain the survival benefit of organized inpatient (stroke unit) care?: further analysis of a systematic review. Stroke 2007;38:2536-40.

19. Steiner T. Stroke unit design: intensive monitoring should be a routine procedure. Stroke 2004;35:1018-19.

20. Indredavik B. Intensive monitoring should not be the routine. Stroke 2004;35:1019-20.

21. Eriksson M, Appelros P, Norrving B, et al. Assessment of functional outcome in a national quality register for acute stroke. Stroke 2007;38:1384-6.

22. Appelros $\mathbf{P}$, Terént $A$. Characteristics of the National institute of Health Stroke Scale: results from a population-based stroke cohort at baseline and after one year. Cerebrovasc Dis 2004;17:21-7.

\section{Stay a step ahead with Online First}

We publish all our original articles online before they appear in a print issue. This means that the latest clinical research papers go straight from acceptance to your browser, keeping you at the cutting edge of medicine. We update the site weekly so that it remains as topical as possible. Follow the Online First link on the home page and read the latest research. 